\title{
In margine a un'epidemia: risvolti linguistici di un virus
}

\section{Claudio Marazzini}

PUBBLICATO: 09 MARZO 2020

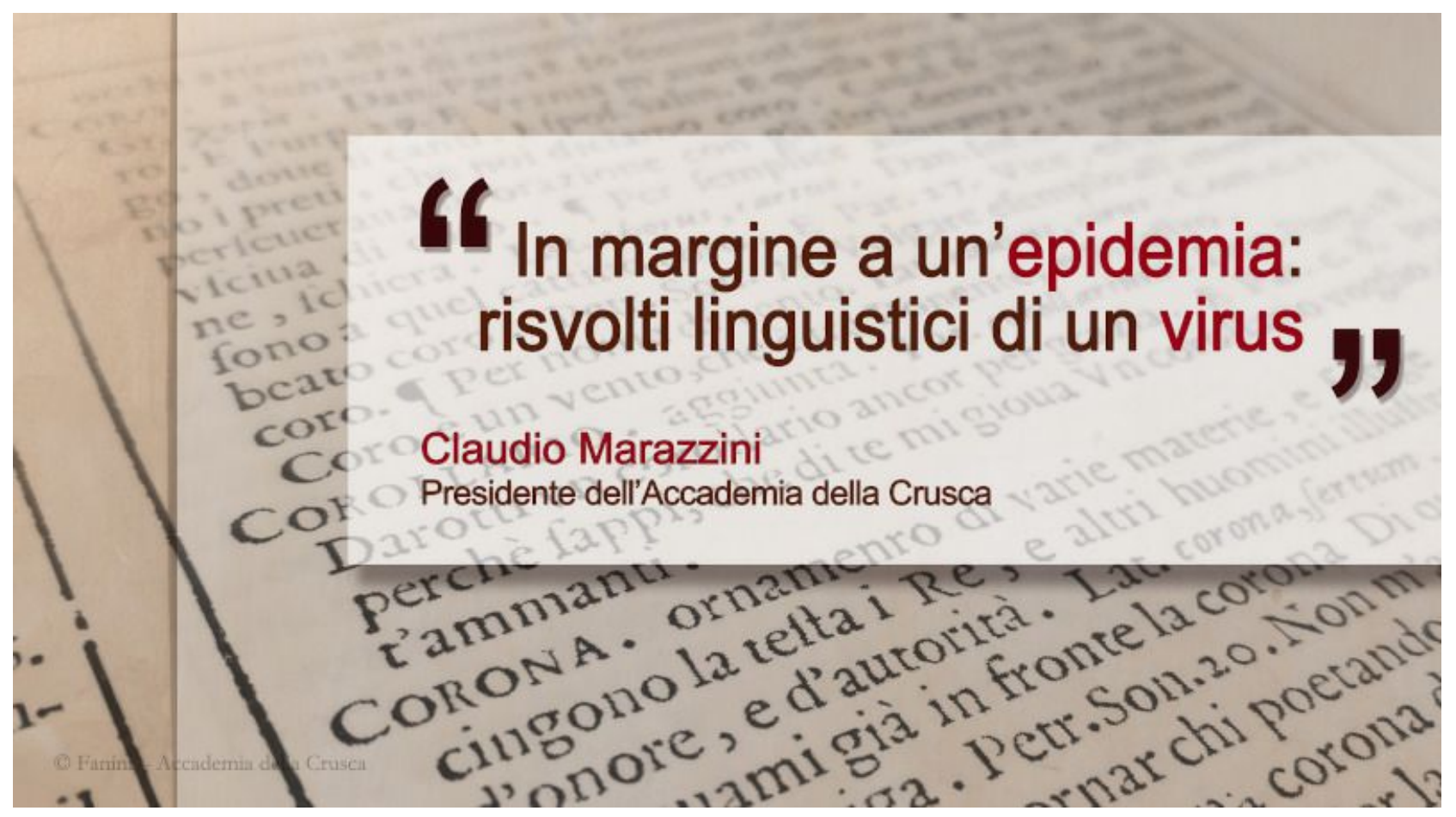

A modo di scusa

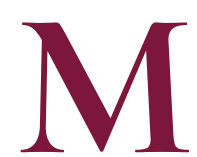

i permetterò di toccare alcuni temi linguistici connessi all'epidemia di Covid-r9, sperando di non urtare, con questo intervento un po' marginale, la sensibilità di chi sta soffrendo per l'emergenza. Dovrebbero forse aver la parola in questo momento solo gli esperti di medicina e di catastrofi. Probamente i linguisti sono per ora superflui. Si consideri tuttavia questa chiacchierata come un modo per riflettere sull'attualità, smorzando un po' la tragicità della situazione, cosi come fecero i dieci giovani del Decameron che scelsero di raccontare novelle al tempo della grande peste del i348. Inoltre si pensi a una verità ineliminabile: ogni evento umano ha riflessi che toccano la lingua, perché attraverso la lingua gli uomini prendono coscienza dei fatti, li soppesano, li giudicano, ne traggono conseguenze. Le tracce dei fatti restano sempre appiccicate alle parole.

\section{Coronavirus: non è soltanto un latinismo}

Un riconoscimento sul campo: il linguista più celere nell'intervenire sull'attualità è stato questa volta Salvatore Claudio Sgroi. Questo studioso, di cui apprezziamo appieno la sagacia (anche se a volte è entrato in polemica con l'Accademia della Crusca: ricordo la questione di "qual é/qual'é"), il 28 febbraio si è espresso nel blog di Fausto Raso con la nota Qual(')é l'origine di Coronavirus?. In questo intervento, tutto sommato abbastanza accademico per un blog popolare, ha esaminato il coronavirus nella lessicografia italiana ed estera, giungendo alla conclusione che la parola non è un 'latinismo', come si ripeteva spesso, ma un anglismo. Cosi Sgroi: "L'ordine dei due componenti del composto binominale coronaVirus s.m. 'virus a forma di corona', con la testa semantica cioè a destra rispetto al 
determinante corona, doveva invero insospettire i lessicografi sulla correttezza dell'etimo sincronico in una lingua come l'italiano, caratterizzata dall'ordine delle parole Soggetto-Verbo-Oggetto, e quindi con i composti tipicamente costruiti con testa a sinistra (cfr. capostazione). E in effetti, coronavirus è un composto esogeno (non già endogeno), ovvero un 'dono' dell'inglese", seppure coniato mediante elementi latini. Non a caso, l'attestazione più antica nota era proprio in lingua inglese, alla data del I968, registrata anche dall'Oxford dictionary. La più antica attestazione per ora nota in italiano è ı970, sulla base di un articolo della "Stampa" citato nel sito Treccani.

\section{Il coronavairus del ministro Di Maio: un inutile linciaggio}

Il secondo intervento di Sgroi, nel medesimo blog, è del 2 marzo; prende lo spunto da un fatto di cronaca: il ministro degli esteri Luigi Di Maio, durante un incontro all'estero, il I2 febbraio, parlando in italiano, ha pronunciato in pubblico il nome del coronavirus all'inglese, come "coronavairus". La reazione dei giornali e della Rete è stata molto intensa, secondo lo stile dei media, con una buona dose di sbeffeggiamenti. Salvatore Sgroi, linguista controcorrente e libertario, è intervenuto a difesa con una tesi collegata al proprio precedente intervento del 28 febbraio: se coronavirus è un anglismo, non è un peccato mortale pronunciarne il nome allinglese.

La voce di questo linguista è stata forse l'unica che si è levata a difesa dell'uomo politico. Ho espresso subito all'amico Sgroi il mio consenso, perché condivido perfettamente la sua difesa condotta contro chi magari dimentica che altre parole anglo-latine vengono comunemente anglicizzate, come massmedia pronunciato "mass-midia", o Juventus stadium pronunciato "Juventus stedium".

La conclusione di Sgroi, sostanzialmente condivisibile, è la seguente:

Trovandosi dinanzi a un termine inglese (costruito con elementi latini), di Maio, - consapevole a differenza dei suoi ipercritici (si potrebbe anche sostenere) che si trattava di un anglicismo, - si è comportato come un parlante normalissimo che ha adattato la pronuncia inglese all'italiano, cioè 'coronavairus'. Muovendo dallo scritto, o basandosi sulla pronuncia ortografica certamente più comune, avrebbe potuto dire anche 'coronavirus'. Ma ha fatto un'altra scelta. Che può non piacere, ma che non può certamente essere oggetto di critiche infondate o di aggressioni verbali".

Cosi Sgroi.

Mi distaccherei da questo equilibrato giudizio solo per sottolineare che la scelta del ministro resta discutibile e poco opportuna, ed è ascrivibile alla categoria di quello che i linguisti chiamano "snobismo": avrà sentito pronunciare cosi da colleghi o esperti esteri, e l'ha ripetuto a sua volta in italiano. Di fatto, in tutto il mondo, chi usa l'inglese, non dice solo "coronavairus" (pronuncia regolarmente registrata nell'Oxford dictionary), ma anche dice "vairus" per "virus". Però in Italia la pronuncia "vairus" non ha corso. Ciò significa che gli italiani, in questo caso, per fortuna, a differenza di quanto accadde per la scelta di "stedium" e "midia", non hanno avvertito virus e coronavirus come anglismi. Quindi non si tratta di scegliere come si vuole, ma di attenersi a un uso stabile, consolidato e dominante. Del resto lo stesso Di Maio, dopo la campagna di stampa contro la sua pronuncia anglicizzante (e Sgroi ha passato in rassegna tutte le testate intervenute sul tema) sembra aver cambiato strada. Credo abbia fatto bene a far cosi.

\section{Produttività e invenzione linguistica: la lingua non si ferma mai}

Ci sono stati sporadici tentativi di italianizzazione dell'ordine dei componenti di coronavirus. Ho sentito alla radio un esperto, di cui purtroppo non ho annotato il nome, che ha detto "virus di corona", cioè ha italianizzato l'ordine dei componenti del sintagma. In Rete si trovano anche diverse attestazioni di virus a corona.

La lingua non si ferma mai, anche a rischio di essere dissacrante e politicamente scorretta. Lo stesso 
Sgroi, in un'intervista nel sito "Libreriamo", ha avuto modo di ricordare il gioco di parole introdotto nella stampa inglese, "dove è apparso anche crownavirus: un gioco di parole con crown verbo "incoronare, + a virus 'un virus". Lo scherzetto linguistico sul nome e sulla forma del virus non è da poco, in un paese dotato di monarchia.

Nel suo primo intervento Sgroi aveva avuto modo di rilevare la possibile "produttività linguistica" (nel senso che i linguisti danno a questa espressione) di coronavirus, che ha già prodotto il neologismo Fontanavirus ("Il Fatto quotidiano" del 27 febbraio), dopo l'apparizione in mascherina del presidente della Lombardia.

L'Organizzazione mondiale della sanità il giorno is febbraio ha reso ufficiale il nome tecnico COVIDI9 per la malattia, mentre il virus si chiama ora Sars-Cov-2. Perché tutto questo è rilevante? Lo spiega assai bene il Ministero della Salute nel suo sito, citando il Direttore generale dell'OMS, Tedros Adhanom Ghebreyesus: "Avere un nome è importante per impedire l'uso di altri nomi che possono essere inaccurati o rappresentare uno stigma [...]. Dovevamo trovare un nome che non fosse di un luogo geografico, di un animale, di un individuo o di un gruppo di persone, che fosse pronunciabile e legato alla malattia". I nomi, insomma, sono sempre importanti. Ormai tutti sanno (ma non sarà male ripeterlo) che COVID-ıg è l'acronimo di Co (corona); Vi (virus); D ('disease', malattia); "Ig" è l'anno di identificazione del virus. Ovviamente l'acronimo è costruito sull'inglese.

\section{La soddisfazione di Incipit per "lavoro agile"}

Le conseguenze linguistiche di una crisi possono essere le più imprevedibili. Pur nel contesto tragico, una soddisfazione è giunta inattesa al gruppo Incipit, il nucleo di linguisti collegato alla Crusca impegnato nel suggerire equivalenti italiani delle parole straniere che rischiano di entrare nella comunicazione pubblica. Una delle misure indicate come utili per contrastare l'epidemia è infatti il lavoro svolto da casa per via telematica, cioè quello che in inglese si chiama smart working, espressione che Incipit aveva suggerito di ribattezzare lavoro agile. Nei vari interventi pubblici più recenti, le due denominazioni si stanno affrontando con alterne fortune, ma lavoro agile pare reagire bene: è stato adoperato da parlanti qualificati e dotati di prestigio, e risulta assumere persino una posizione di vantaggio statistico sull'avversario inglese, a cui pure molti restano fanaticamente abbarbicati. La lotta senza quartiere al virus diventa anche il teatro della competizione tra queste due forme linguistiche.

\section{Lunga storia del virus}

Lo storico della lingua, comunque resta affascinato non solo dall'immediata attualità, ma soprattutto dalla storia, che si snoda su tempi lunghi. Da questo punto di vista, è interessante di per sé la lunga evoluzione della parola "virus", che sembra destinata a diventare, purtroppo, la parola dell'anno. Il latinismo, in questi giorni, banalmente è stato interpretato soprattutto come "veleno". In realtà le cose sono più complicate. In latino il virus era piuttosto il "succus nativus et vitalis cujusque rei", come si legge nel Forcellini. Poteva essere sia un succo salutare, sia nocivo e portatore di malattia. L'uso maggioritario fu quello negativo: "Saepissime dicitur de succo noxio et venenato", come suggerisce ancora il Forcellini. Per secoli questo umore nocivo fu considerato portatore di malattie contagiose, senza che si capisse bene perché e come ciò accadesse. Che cosa agiva dentro il misterioso "virus"? L'azione era dovuta a una sostanza o una forma di vita? Non lo si seppe fino alla scoperta dei batteri (il cui nome, grecismo-latinismo, è legato alla forma di "bastoncino", come del resto il nome di bacillo: cfr. B. Migliorini, Parole d'autore. Onomaturgia, Firenze I977, pp. 20 e 22). Nell'Ottocento l'azione dell'umore malefico fu finalmente spiegata mediante il riconoscimento di forme di vita microscopica prima sconosciute. Ma la scoperta dei batteri non era ancora quella dei virus, perché questi ultimi sono invisibili al microscopio ottico. Ci volle altro tempo per distinguere tra queste due diverse entità, oggi classificate fra l'altro in modo radicalmente differente, solo la prima tra le forme di vita. 
Nei dizionari dell'Ottocento, per esempio nel Tramater (i840 e i856), la voce Virus compare a lemma, ma con il rinvio a "Virulenza", quest'ultima definita ancora come "Umor velenoso, cioè Veleno animale morboso e maligno supposto più che conosciuto, che si considera come l'agente di trasmissione delle malattie contagiose propriamente dette" .

I virus, com'e noto, sono stati invisibili fino all'avvento del microscopio elettronico. Dal grande corpus degli Scienziati italiani allestito presso l'Accademia della Crusca (con la collaborazione del gruppo di ricerca dell'Università del Piemonte Orientale, da me diretto fino al febbraio di quest'anno) traggo una definizione di virus che non si trova nei dizionari italiani, e che si deve a Giulio Bizzozero, grande medico della seconda metà del sec. XIX, fondatore della scuola pavese di medicina, collaboratore di Mantegazza, poi professore a Torino. Bizzozero racconta come il problema della contagiosità dovuta al "virus", inteso più o meno secondo la definizione che abbiamo letto nel Tramater, fu affrontato dal medico francese Villemin, il quale, nel i865, inoculò sotto la pelle di conigli sani e robusti un po' di materia tubercolare tolta dall'uomo, e vide che gli animali si ammalavano e morivano di tubercolosi. La notizia di questo esperimento ebbe eco immensa nel mondo scientifico, ricorda Bizzozero, ma non fu ancora risolutiva. Si confrontavano avversari e sostenitori della tesi del contagio, anche perché non si era ancora capito quale fosse la vera natura della materia "virus" che trasmetteva la malattia. Solo nel I882 Kock diede notizia dei bacilli tubercolari che aveva potuto individuale e (finalmente) vedere. Così commentava Bizzozero nel ı 899: "La scoperta di Koch ha così integrato quella di Villemin, dando forma e significato di essere vivente a quel quid misterioso che si nascondeva sotto il nome di virus". Ecco la calzante definizione di Bizzozero a cui facevo riferimento: come si vede, nella sua descrizione si dava finalmente per superata l'impressione di quel tal "quid misterioso" fino allora attribuito allo sfuggente "virus". Era pero ancora impossibile distinguere virus e batteri. Consultando il data-base di cui ho parlato, trovo la distinzione affiorare appena, come supposizione, nel celebre manuale del grande genetista e biologo Giuseppe Montalenti (ed. 1939). Montalenti usa una parola nuova, ultravirus, e scrive che "forse esistono anche organismi - se tali veramente sono gli ultravirus, o virus filtrabili, che degli esseri viventi hanno molte proprietà - i quali non rivestono alcuna forma visibile con i mezzi di osservazione di cui oggi si dispone". I virus, di cui Pasteur aveva supposto l'esistenza, non erano ancora visibili. Nel I982, lo stesso Montalenti poteva parlare finalmente dei virus come qualche cosa di visibile ai nuovi strumenti, interrogandosi sull'antico problema della "generazione spontanea" e della nascita della vita sulla terra: "La scoperta dei virus filtrabili, o ultravirus, molto più piccoli e più semplici dei batteri (sono invisibili al microscopio ottico, per fotografarli occorre il microscopio elettronico) ha dato qualche speranza nel senso di poterli considerare forme elementari della vita".

Come si vede, il termine virus è andato sempre più specializzandosi nei secoli, dal significato generico di 'umore', fino a diventare "umore maligno e velenoso", per poi confondersi con i batteri, e successivamente diventare il nome di un'entità precisa infinitamente più piccola dei batteri e a sua volta loro parassita. Nel frattempo, si è sviluppato un ampio uso metaforico di virus, registrato già dai dizionari dell'Ottocento (ad es. il Tramater sopra citato), come forza nociva e malefica di qualunque tipo (il GDLI ha tra gli altri un esempio di Benedetto Croce: "il virus dell'odio"). L'ultima evoluzione divirus, nell'italiano moderno, a partire dagli anni Ottanta del secolo scorso, è stato il passaggio allinformatica, per indicare i programmi truffaldini che infettano i computer. Questa risemantizzazione risulta produttiva, ed ha prodotto virale nel senso speciale che si usa in Rete, per indicare un contenuto o un meme che si diffonde in maniera irresistibile.

\section{Il contagio politicamente corretto}

L'ultimo risvolto linguistico a cui farò riferimento riguarda un intervento di Saro Trovato nella rivista in Rete "Libreriamo", dove si preoccupa che la parola "contagiato" possa nascondere o veicolare una 
sorta di discriminazione pericolosa. In precedenza, Salvatore Galeone di "Libreriamo" si era rivolto a me, in un'intervista in cui esplorava le possibilità di trovare alternative linguistiche ai termini "contagiato", che poteva essere sostituito con "affetto da...". Nell'intervista avevo fra l'altro discusso l'opinione di coloro che attribuivano al termine coronavirus un effetto terrorizzante, che certo non è prodotto da parole come "influenza", anche se spesso l'affezione che ora sappiamo essere Covid-I9 si manifesta appunto come un'influenza. In quel momento, la gravità dell'epidemia allarmava meno di oggi. Per fortuna, nell'intervista mi ero espresso con molta cautela, ammettendo che la scelta delle parole può essere più o meno allarmante (anche epidemia spaventa meno di pandemia), ma che tale scelta non dipende certo dai linguisti, ma è legata agli effetti che le autorità mediche e politiche vogliono produrre nella popolazione, accentuando il sentimento del rischio o attenuandolo. Non si tratta insomma di un banale problema di "politicamente corretto" la cui soluzione possa essere giudicata univocamente.

Vedremo dunque come andrà a finire. Nel frattempo, anche l'Accademia della Crusca, come le altre istituzioni dello stato, ha adottato le misure previste, ed ha chiuso l'accesso pubblico alla biblioteca, all'archivio e agli incontri. Speriamo che tutto ciò non duri troppo.

Note:

I. Nell'ed. I856 un insidioso refuso trasformò "conosciuto" in "consunto".

\section{Cita come:}

Claudio Marazzini, In margine a un'epidemia: risvolti linguistici di un virus, "Italiano digitale", 2020, XII, 2020/1 (gennaio-marzo)

DOI: $10.35948 / 2532-9006 / 2020.3303$

Copyright 2020 Accademia della Crusca

Pubblicato con licenza creative commons CC BY-NC-ND 